\title{
CORRECTIONS
}

\section{An 81 year old man with a blistering rash}

In the first paragraph of this Endgames quiz we should have stated that the patient had a history of hyperthyroidism, not "hypothyroidism" as was published (BMJ 2013;346:f522, doi:10. 1136/bmj.f522).
Cite this as: BMJ 2013;346:f1667

๑ BMJ Publishing Group Ltd 2013 